\title{
Chaperone-Based Therapeutic Target Innovation: Heat Shock Protein 70 (HSP70) for Type 2 Diabetes Mellitus
}

This article was published in the following Dove Press journal: Diabetes, Metabolic Syndrome and Obesity: Targets and Therapy

\author{
W. Riski Widya Mulyani (iD' \\ Made Indira Dianti Sanjiwani' \\ Sandral \\ I Putu Yuda Prabawa $\left(\mathbb{D}^{2}\right.$ \\ Anak Agung Wiradewi \\ Lestari (iD) ${ }^{2}$ \\ Desak Made Wihandani ${ }^{3}$ \\ Ketut Suastika ${ }^{4}$ \\ Made Ratna Saraswati ${ }^{4}$ \\ Agha Bhargah (ID) \\ Ida Bagus Amertha Putra \\ Manuaba $\mathbb{I D}^{6,7}$ \\ 'Faculty of Medicine, Universitas \\ Udayana, Bali, Indonesia; ${ }^{2}$ Department of \\ Clinical Pathology, Faculty of Medicine, \\ Universitas Udayana, Sanglah General \\ Hospital, Bali, Indonesia; ${ }^{3}$ Department of \\ Biochemistry, Faculty of Medicine, \\ Universitas Udayana, Bali, Indonesia; \\ ${ }^{4}$ Department of Internal Medicine, \\ Faculty of Medicine, Universitas Udayana, \\ Sanglah General Hospital, Bali, Indonesia; \\ ${ }^{5}$ Cardiology Department, Faculty of \\ Medicine, Universitas Udayana-Sanglah \\ General Hospital, Bali, Indonesia; \\ ${ }^{6}$ International Ph.D Program in Medicine, \\ College of Medicine, Taipei Medical \\ University, Taipei, Taiwan; ${ }^{7}$ Medical and \\ Health Education Unit, Faculty of \\ Medicine, Universitas Udayana, Bali, \\ Indonesia
}

Correspondence: Anak Agung Wiradewi Lestari

Department of Clinical Pathology, Faculty of Medicine, Universitas Udayana, Sanglah General Hospital, Bali, Indonesia

Email wiradewilestari@gmail.com

\begin{abstract}
Type 2 diabetes mellitus (T2DM) is still a global health problem. Current T2DM treatments are limited to curing the symptoms and have not been able to restore insulin sensitivity in insulin-sensitive tissues that have become resistant. In the past decade, some studies have shown the significant role of a chaperone family, heat shock protein 70 (HSP70), in insulin resistance pathogenesis that leads to T2DM. HSP70 is a cytoprotective molecular chaperone that functions in protein folding and degradation. In general, studies have shown that decreased concentration of HSP70 is able to induce inflammation process through JNK activation, inhibit fatty acid oxidation by mitochondria through mitophagy decrease and mitochondrial biogenesis, as well as activate SREBP-1c, one of the lipogenic gene transcription factors in ER stress. The overall molecular pathways are potentially leading to insulin resistance and T2DM. Increased expression of HSP70 in brain tissues is able to improve insulin sensitivity and glycemic control specifically. HSP70 modulation-targeting strategies (including long-term physical exercise, hot tub therapy (HTT), and administration of alfalfa-derived HSP70 (aHSP70)) in subjects with insulin resistance are proven to have therapeutic and preventive potency that are promising in T2DM management.
\end{abstract}

Keywords: type 2 diabetes mellitus, HSP70, insulin resistance

\section{Introduction}

Type 2 diabetes mellitus (T2DM) is a metabolic disease that still becomes a global health issue. Based on the WHO report in 2014, 442 million people in the world suffer from diabetes, with $90 \%$ of the cases are T2DM. ${ }^{1}$ On the other hand, patients of T2DM in Indonesia have reached 10 million people. ${ }^{2,65}$

T2DM treatments to this date, including oral antidiabetics (metformin, sulfonylurea, thiazolidinedione), both monotherapy and combination, and insulin injection, are targeted to establish normal blood glucose level. ${ }^{3,4}$ However, conventional medications are limited to curing the symptoms and have not been able to solve the main problem, which is insulin resistance. ${ }^{5}$ Other than that, many studies reported some side effects associated with the conventional treatments, such as hypoglycemic due to sulfonylurea and insulin injection, as well as idiosyncratic hepatotoxic after consuming thiazolidinedione. ${ }^{6-8}$ These problems hence raise the urgency to discover new treatment method in curing T2DM, which is not only limited to curing the symptoms and low with side effects, yet also one that is the potential to restore insulin sensitivity in the resistant tissue. 
In the past decade, some studies have shown the significant role of a family chaperone, heat shock protein 70 (HSP70), in the pathogenesis of insulin resistance that leads to T2DM. ${ }^{9,10}$ HSP70 is a cytoprotective molecular chaperone that functions in protein folding and degradation. Induction, transcription, and translation of this molecule experience a decrease in the obese animal model and other metabolic diseases related to insulin resistance. ${ }^{11}$ This shows that HSP70 has therapeutic and preventive potency in managing T2DM. HSP70 plays a role in insulin resistance pathogenesis through inflammation, mitochondrial function, and ER stress. ${ }^{12}$ Decreased concentration of HSP70 is able to induce inflammation through JNK activation, inhibit fatty acid oxidation by mitochondria through mitophagy decrease and mitochondrial biogenesis, as well as to increase SREBP-1 activation, one of the lipogenic gene transcription factors in ER stress. ${ }^{13}$ In addition, increased expression of HSP70 in brain tissues is able to increase insulin sensitivity and glycemic control specifically. ${ }^{13}$

The correlation between insulin resistance, T2DM, and HSP70 hence fosters new hope in T2DM management. As the therapy target, HSP70 is the potential to be modulated through several interventions that are possible to be implemented. Those interventions include long-term physical exercise, hot tub therapy (HTT), and administration of alfalfa-derived HSP70 (aHSP70). ${ }^{13-15}$ Further understanding regarding HSP70 role in T2DM pathogenesis may disclose new possibilities to modulate HSP70 in the future. Therefore, the authors are interested in reviewing deeper regarding HSP70 role in T2DM pathogenesis and its role as innovation for therapy target in T2DM patients.

\section{HSP70 and Its Role in T2DM Pathogenesis}

HSP70 is one of the family chaperones produced normally in lymphocyte, macrophage, epithelium, dendrite, muscle, and hepatocyte. ${ }^{9,16}$ This protein molecule with $70 \mathrm{kDA}$ weight has a function in maintaining other protein homeostasis and works ATP dependently. ${ }^{17,18}$

Some chaperones in the HSP70 family are classified based on their genes and locations within the cell. HSP72 and $\mathrm{Hsc70}$ are located in the nucleus and cytoplasm, BiP (Grp78) is located in the ER, while Grp75 (mtHSP70) is situated in mitochondria. ${ }^{19}$ In normal condition, HSP70 is involved in protein folding and transport to organelles, defect protein recognition and degradation, as well as KFPRQ sequence-containing protein marking to be degraded in the lysosome. ${ }^{20}$ In order to run its function, HSP70 binds to the hydrophobic zone during protein synthesis to prevent any protein misfold. ${ }^{21,22}$ However, when cell stress occurs, HSP70, which is initially located in the cell (iHSP70), is able to migrate to circulation (and changes its name into eHSP70) through several mechanisms. HSP70 translocation out from the cell happens through active mechanism, lipid rafts, and exosome. This migration allows iHSP70, which was initially an anti-inflammatory molecule, to alter into proinflammatory eHSP70. ${ }^{23}$

Decreased iHSP70 and increased eHSP70 expression are found in patients with obesity and metabolic diseases, including T2DM. This has been proven by several studies. $^{24,25}$ Others have also explained that HSP70 modulation can affect blood glucose levels by increasing insulin sensitivity. ${ }^{10,14,26}$ Rodrigues-Krause et al measured iHSP72 concentration and HSF-1 expression in skeletal muscle, as well as eHSP72 in blood plasma in subjects with obesity, T2DM-non obesity, and T2DM-obesity. ${ }^{23}$ It was reported that iHSP72 in skeletal muscle is decreasing in the T2DM group. The decrease happens significantly in the T2DM-obese group compared to T2DM-non obese. ${ }^{23}$ HSF-1, one of the transcription factors of HSP72, also is downregulated in subjects with T2DM. ${ }^{27}$ HSF-1 expression in skeletal muscle of obese patients is found five times lower than the obese control group. Inversely proportional to iHSP72 and HSF-1, eHSP72 plasma concentration experiences a double increase in T2DM-obesity group when compared to obese control and T2DM-non obese group. ${ }^{23}$ This escalation is associated with protein defect and oxidative stress level that coincides with the pathogenesis of the disease. ${ }^{23,27}$

\section{HSP70 Role on Inflammation in T2DM Pathogenesis}

HSP70 affects inflammation and insulin resistance through several pathways (Figure 1). eHSP70 plays its role as a ligand to TLR2 and TLR4 in the surrounding cells. ${ }^{10}$ This will lead to the activation of two pathways, namely MyD88 and TIRAP, which will give downregulation signals to NF- $\mathrm{BB}$ through IRAK4, TRAF6, and IKK that also induce the activation of JNK through MEKK 4/7. ${ }^{28}$ Signals from eHSP70 also stimulate the production of NO and other cytokines, such as TNF $\alpha$ and IL1 $\beta .{ }^{9}$

JNK activation as the effect of eHSP70 attachment to TLR will initiate the inflammation reaction on the cells. ${ }^{9,29}$ JNK itself consists of JNK1, JNK2, and JNK3. However, 


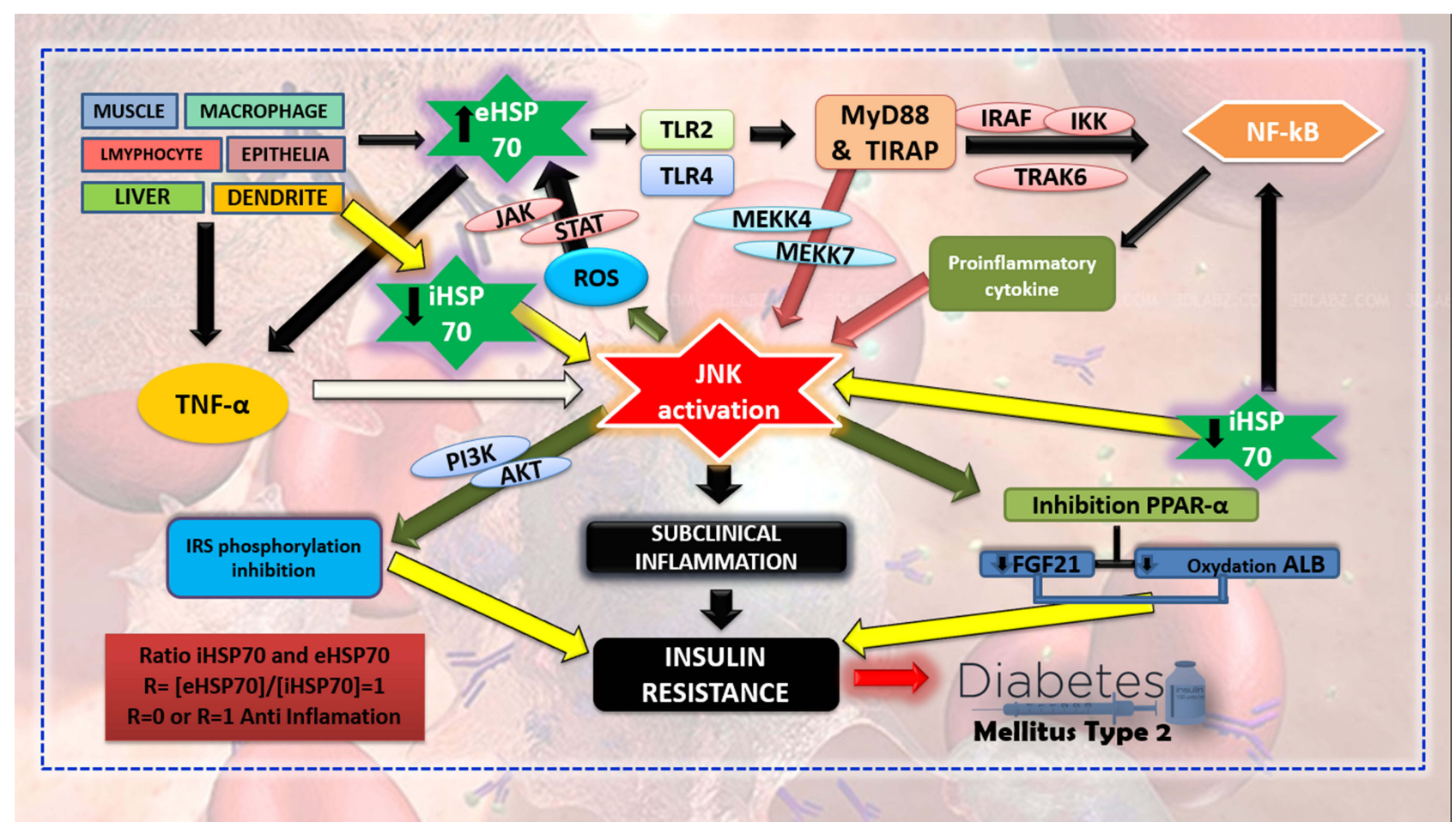

Figure I Role of iHSP70 and eHSP70 on the inflammatory process in T2DM pathogenesis.

JNK1 and JNK2 are the most responsible types of insulin resistance. JNK activation will induce three mechanisms that result in insulin resistance. First, JNK1/2 can inhibit insulin receptor (IRS-1) phosphorylation and reduce signalling regulation of PI3K-AKT towards insulin. Second, JNK1/2 activation may increase cytokine M1 expression by a proinflammatory macrophage. Third, JNK1/2 activity in the liver will inhibit PPAR- $\alpha$, decrease the production of FGF21, and fatty acid oxidation. ${ }^{30}$ Other than that, JNK activation may inhibit the respiration process in mitochondria, resulting in increased production of reactive oxygen species (ROS). ${ }^{13,31}$ Increased production of ROS may affect eHSP70 expression. ROS can trigger eHSP70 expression through the JAK/STAT pathway hence it will produce inflammatory responses. $^{32}$

Inflammation is an event induced by JNK activity, and it is possible to be intervened by HSP70. The role of iHSP70 is known to inhibit JNK activation through several mechanisms, such as direct protein contact on JNK. ${ }^{13}$ This process will result in disturbances on the JNK function that will result in insulin receptor phosphorylation and inhibited ROS production. ${ }^{33} \mathrm{cp}$-PGS, a strong anti-inflammatory factor owned by iHSP70, is able to affect the phosphorylation continuity of IRS-1 by inhibiting the IKK pathway. iHSP70 also plays a role in reducing $\mathrm{NF}-\mathrm{\kappa B}$ and $\mathrm{JNK}$ activities in skeletal muscle. This factor is also able to attach directly to the insulin receptor; hence, it increases its sensitivity. ${ }^{9}$

The prior study explained that HSP70 has antiinflammatory activity and is able to lower the ongoing inflammatory process. ${ }^{34}$ iHSP70 and eHSP70 ratio have a crucial role in inflammation. Different concentrations between iHSP70 and eHSP70, where iHSP70 is higher than eHSP70, will decrease the inflammation process that happens. Another study discussed plasma eHSP70 to lymphocyte iHSP70 ratio and its effect on inflammation. The control ratio was set with $\mathrm{R}=[\mathrm{eHSP} 70] /[\mathrm{iHSP} 70]=1$ in resting condition and without stimulation. R-value of more than 5 marks proinflammatory condition, while $\mathrm{R}=0$ or 1 marks anti-inflammatory condition. ${ }^{9}$ This shows that the lower the R-value, the higher will the anti-inflammatory activity, and insulin sensitivity be, due to the direct correlation between HSP70 and insulin activity.

\section{HSP70 Role on Mitochondrial Function in T2DM Pathogenesis}

Insulin resistance is often related to the reduced mass of mitochondria or mitochondrial oxidative function in insulin-sensitive tissues. This hence led to a hypothesis that mitochondrial dysfunction plays a crucial role in promoting 
insulin resistance. ${ }^{35-37}$ Several studies showed that overexpression in HSP72 is able to improve mitochondrial dysfunction (Figure 2). The improvement happens through several mechanisms, such as improving fatty acid oxidation, improving enzyme activity in mitochondria, and mitochondrial biogenesis. $^{38-41}$

A study measured oxidative capacity in skeletal muscle of wile type rats (WT) and transgenic rats with HSP72 overexpression (HSP72+/+) using the maximum activity of two major mitochondrial enzymes, citrate synthase (CS) and b-hydroxyacyl-CoA dehydrogenase (b-HAD). It was proven that the maximum activity of both of the enzymes is higher in HSP72 +/+ rather than WT rats. ${ }^{42}$ The data represent the role of HSP72 in improving fatty acid oxidative capacity in rats skeletal muscle; hence, it is able to prevent body weight gain and insulin resistance in the rats. Darren et al examined HSP72 +/+ and WT rats, with each group being given high-fat diet (HFD) $45 \%$ for 10 weeks. HFD induction is capable of increasing body weight, epidydimal fat mass, intramuscular lipid accumulation, as well as to induce insulin resistance in WT rats. A similar effect is not found in HSP72 +/+ rats. HSP72 +/+ rats have improved numbers of mitochondria up to $50 \%$ and significantly increased expression of mRNA Tfam, an essential gene in mitochondrial biogenesis. ${ }^{43}$
Another study found that there is an increase in phosphorylation and AMPK (AMP-activated protein kinase) activity, as well as a significant increase of SIRT1 (Sirtuin 1) in HSP72 +/+ rats skeletal muscle. AMPK and SIRT1 are the regulators of cellular energy status that is important in oxidative metabolism and mitochondrial biogenesis. ${ }^{43,44}$ Both play a role in activating PGC- $1 \alpha$, which then triggers mitochondrial biogenesis through the Jrfl-Tfam pathway or induces fatty acid oxidative process through PPAR $\alpha$. The fatty acid oxidation process will reduce the accumulation of free fatty acid, such as DAG and CER, thus will reduce insulin resistance. $^{45-47}$

Aside from improving enzyme activity that leads to restoring mitochondrial oxidative function and improving mitochondrial biogenesis, HSP72 induction may mediate the quality improvement of mitochondria by regulating mitophagy, a degradation process of dysfunctional mitochondria that are targeted through autophagy. One study that used rat model with low expression of HSP72 in skeletal muscle shows the low ability of the rats to degrade mitochondria through mitophagy. ${ }^{48}$ HSP72 absence leads to reduced chaperone translocation to depolarised mitochondria; hence, Mfn2-HSP72 complex was not formed. This event prevents translocation of Parkin, a ubiquitin E3 ligase, to help in the formation of Mfn2 complex in depolarised mitochondria.

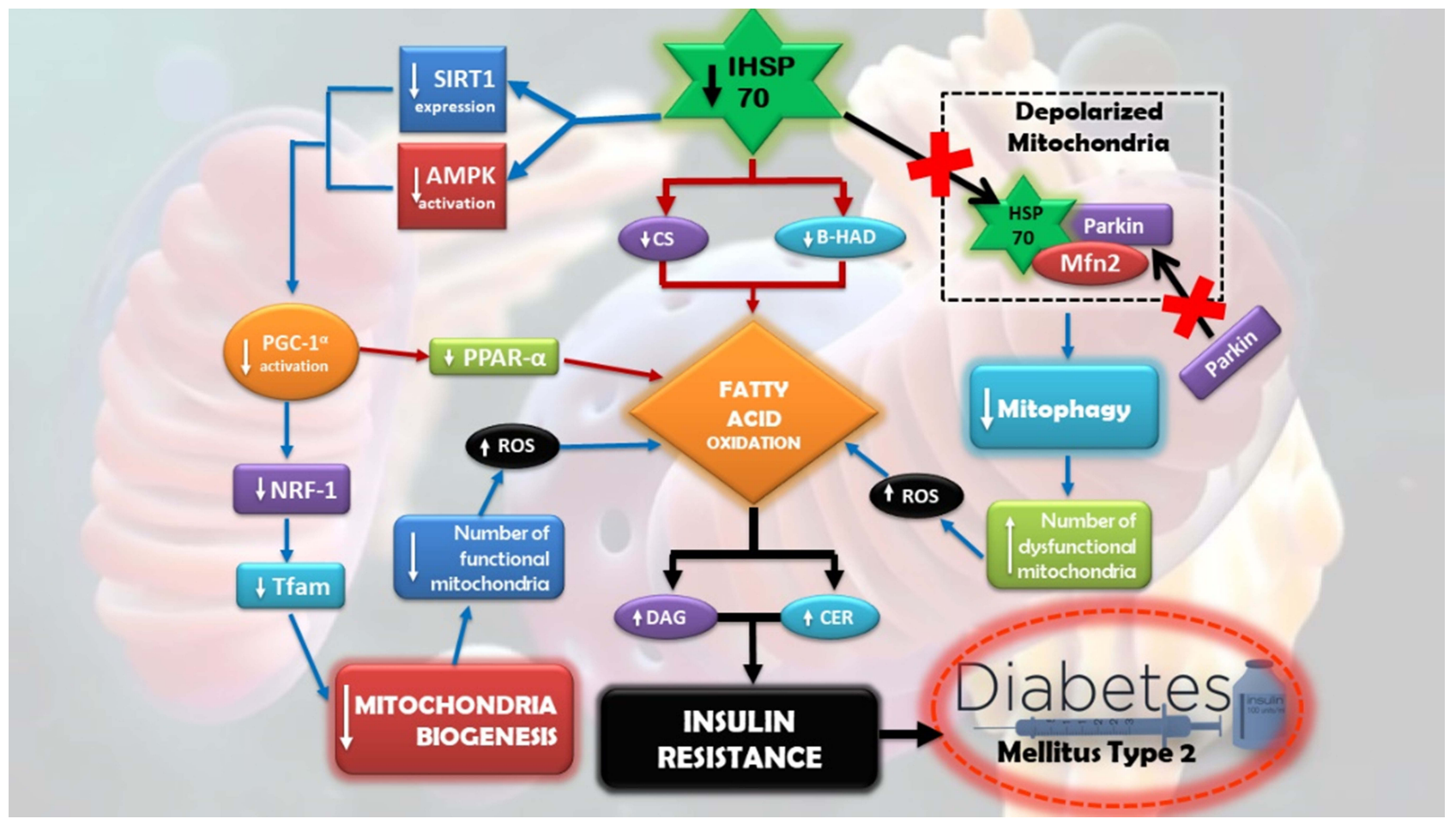

Figure 2 HSP70 in mitochondrial function in T2DM pathogenesis. 
The series of inhibition resulted in the disturbed process of normal mitophagy in rats with low HSP72. The rats also exhibit dysmorphic and enlarged mitochondria. The condition led to decreased capacity of muscle respiration and increased lipid accumulation which in parallel connected with insulin resistance. ${ }^{48}$

\section{HSP70 Role on Endoplasmic Reticulum (ER) in T2DM Pathogenesis}

Endoplasmic reticulum (ER) is an organelle that synthesises membrane and secretes proteins. ${ }^{49,50}$ Any disturbances on ER function, including over-synthesis of protein or accumulation of unfolded and misfolded proteins in ER lumen, are called ER stress. A study done by Hotamisligil et al showed a strong correlation between ER stress and lipogenesis, where most of the lipid is accumulated on the ER of obese rats coming from the lipogenic pathway. ${ }^{51}$ On the other side, ER stress is able to induce proteolytic SREBP-1c cleavage and activate the whole lipogenic program. ${ }^{52}$ Cleavage mechanism and activation are suspected to involve fast degradation of insulin-induced gen 1 (Insig1), a protein that holds SREBP/SCAP (SREBP cleavage-activating protein) complex in the ER membrane. ${ }^{53}$

Lipogenic-inducing chronic ER stress, as observed in the liver of obese animal, will become the main determinant of insulin resistance. ${ }^{51}$ HSP70 role in reducing it is shown on rats with overexpressed hepatic BIP, one of HSP70 family chaperone member in ER. The experimental rats showed attenuation of ER stress, which is then able to decrease SREBP-1c activation and liver triglyceride, as well as to increase insulin sensitivity. SREBP-1c is associated with luminal BIP, where its export to the Golgi body requires BiP dissociation. ${ }^{52}$ Another study showed that fat rats administered with chemical chaperone might have their ER stress reduced and simultaneously have their insulin sensitivity increased. ${ }^{54}$ The overall pathway will be summarised in Figure 3.

\section{HSP70 Expression Role on Brain Tissues in Insulin Sensitivity and Glycemic Control}

HSP70 expression in brain tissues is able to be modulated through intranasal HSP70 administration. The previous study proved that the respective administration is able to improve insulin sensitivity in diabetic rats (Figure 4). This indicates that the method is capable of giving glycemic control effect systemically. Intranasally administered HSP70 will experience uptake through nasal epithelia, then proceed to glomerular from the olfactory bulb. ${ }^{15}$ Past findings explained a hypothesis that the uptake mechanism and the distribution were similar to albumin if observed from its molecular structure. The distribution of albumin happens in whole-brain parts through the transcytosis mechanism. ${ }^{56}$ Besides that, the same mechanism is found on intranasal insulin administration where the insulin enters through diffusion in olfactory epithelial to sub-arachnoid area. This route of insulin administration is also able to penetrate the central nervous system indirectly through the olfactory bulb. ${ }^{56}$

Increased expression of HSP70 in tissues is known to increase insulin sensitivity. ${ }^{54}$ However, a specific mechanism regarding the direct correlation between HSP70 increased

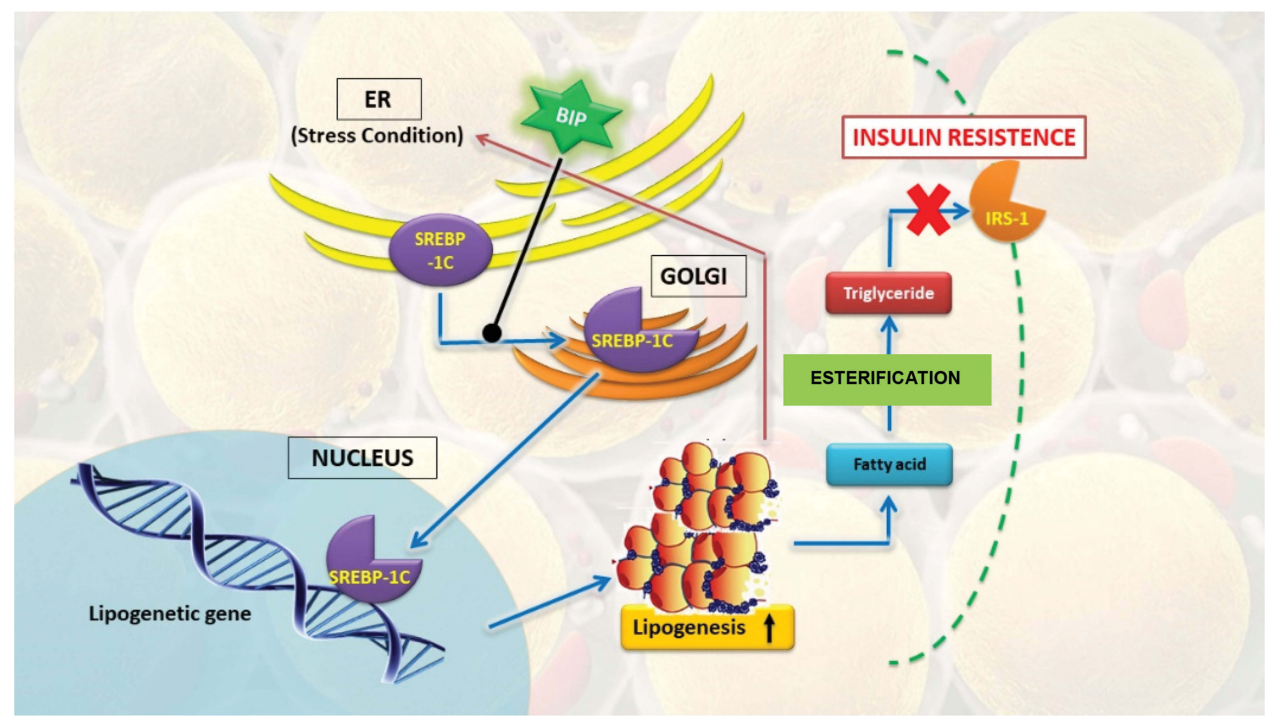

Figure 3 HSP70 role on ER stress in T2DM pathogenesis. 


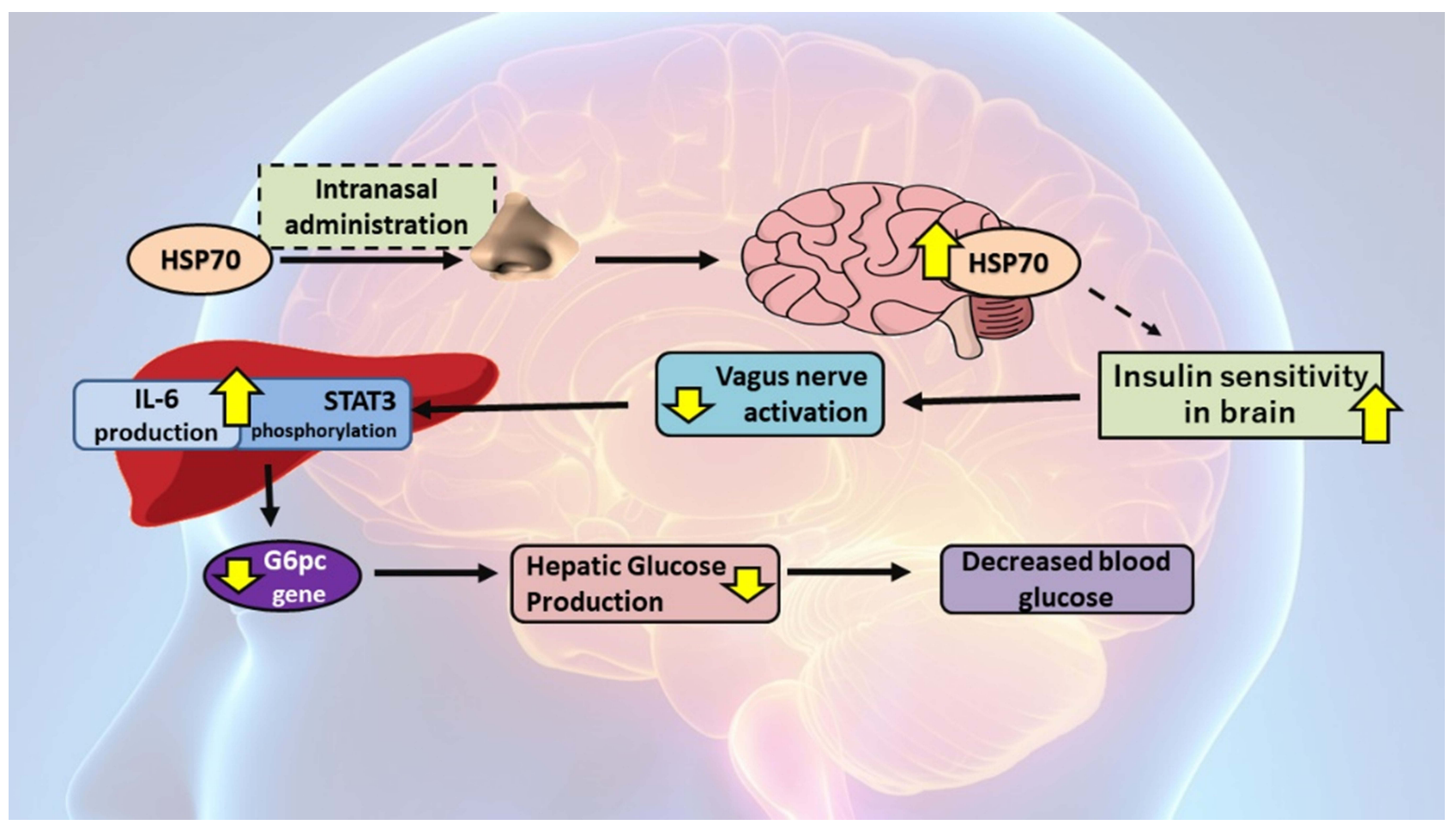

Figure 4 HSP70 expression role on brain tissue in insulin sensitivity and glycemic control.

expression on brain tissues and improved insulin sensitivity in diabetic rats has not been specifically studied. Nonetheless, based on previous research, it is known that increased expression of HSP70 on olfactory bulb, hippocampus, and hypothalamus happened simultaneously with increased insulin sensitivity on peripheral tissues. ${ }^{15}$ This supports the hypothesis regarding the increased expression of HSP70 on the brain to affect insulin sensitivity, both on brain and peripheral tissues.

Another study also proved that improved insulin sensitivity in brain tissues is able to create the regulatory effect of several mechanisms that support glycemic control effect. One of the regulated mechanisms includes gluconeogenesis in the liver. $^{56}$ The process is affected by the insulin receptor on the brain. The sensitisation will suppress the vagus nerve which then stimulates STAT 3 phosphorylation and IL-6 production in the liver. This will lead to the inhibited expression of G6pc gen, a crucial gene in gluconeogenesis. By the end, insulin activity on the brain is able to inhibit hepatic glucose production, which results in decreased peripheral blood glucose. ${ }^{57}$

\section{HSP70 Modulation as a Therapy Target in T2DM}

Strategies targeting HSP70 modulation in T2DM (longterm physical exercise, HTT, and aHSP70) are capable of maintaining and increasing the expression of HSP70, hence preventing the progression towards more severe T2DM. ${ }^{13-15,58,59}$ Several studies have shown its capability to restore insulin sensitivity. ${ }^{13}$ Therefore, though many of its roles, HSP70 has the promising potency to become the therapeutic target in managing T2DM. Studies related to HSP70-modulating interventions have been summarised in Table 1.

\section{HSP70 Modulation as a Therapeutic Target in T2DM by Long-Term Exercise}

Physical exercise is known to be capable of modulating HSP70. ${ }^{55}$ Although exercise may trigger stress in cells, routine long-term training may increase iHSP70 production in skeletal muscle, liver, kidneys, and heart. ${ }^{5-61}$ Through their study, Noble et al proved the significant increase of HSP70 concentration $(\mathrm{p}<0.05)$ in three rats organs within exercising group, whereas it was $50 \%$ higher in heart, 3.33 times higher in White Gastrocnemius (WG), and 10\% higher in Soleus when compared to control group. ${ }^{20}$ Another study showed that the attenuation of HSP72 expression induced by exercises in skeletal muscle and liver of Otsuka Long-Evans Tokushima Fatty (OLETF) rats, a well-characterised animal model to represent human condition with T2DM, is able to blunt the partial increase of insulin resistance in the whole body. ${ }^{62}$ 
Table I Studies Related to HSP70-Modulating Interventions

\begin{tabular}{|c|c|c|c|c|}
\hline Intervention & $\begin{array}{l}\text { Types of } \\
\text { Research }\end{array}$ & Research Purpose & Results & References \\
\hline Exercise & Human & $\begin{array}{l}\text { Understanding the effect of exercise (cycling } \\
\text { until exhausted) on the expression of HSP72 } \\
\text { mRNA in skeletal muscles. }\end{array}$ & $\begin{array}{l}\text { HSP72 mRNA expression progressively } \\
\text { increased during exercise (cycling). }\end{array}$ & Febbraio et al $^{60}$ \\
\hline Exercise & In vivo & $\begin{array}{l}\text { Understanding the effect of exercise (running } \\
\text { on the treadmill) on HSP72 expression in } 3 \\
\text { different rat organs: heart, soleus, and white } \\
\text { gastrocnemius (WG). }\end{array}$ & $\begin{array}{l}\text { There was a significant increase in HSP70 } \\
\text { expression in the heart and WG in the } \\
\text { exercising group. } \\
(\text { Heart }=77.4 \pm 8.5 \text {; WG }=93.9 \pm 18.4 \text { ) }\end{array}$ & Noble et $\mathrm{al}^{61}$ \\
\hline HTT & In vivo & $\begin{array}{l}\text { Understanding the effect of HTT on HSP70 } \\
\text { expression, lipid profile, antioxidant capacity, } \\
\text { and blood glucose level in diabetic rats. }\end{array}$ & $\begin{array}{l}\text { Some findings included an improved lipid } \\
\text { profile, increased HSP70 expression, and } \\
\text { antioxidant capacity in diabetic rats with HTT. }\end{array}$ & Bathaie et $\mathrm{al}^{63}$ \\
\hline $\begin{array}{l}\text { Alfalfa derived } \\
\text { HSP70 }\end{array}$ & In vivo & $\begin{array}{l}\text { Understanding the effect of aHSP70 (in different } \\
\text { dosage) on insulin sensitivity and blood glucose } \\
\text { level in diabetic rats. }\end{array}$ & $\begin{array}{l}\text { There was an increase in insulin sensitivity in } \\
\text { groups with aHSP70 (14\% at } 10 \mu \text { dosage } \\
\text { and } 40 \% \text { at } 40 \mu \text { dosage). }\end{array}$ & Tytell et al. ${ }^{15}$ \\
\hline
\end{tabular}

\section{HSP70 Modulation as a Therapeutic Target in T2DM by Hot Tub Therapy (HTT)}

HSP70 is also able to be modulated through heat therapy by using hot tub therapy (HTT) method. ${ }^{14,63}$ HTT method does not require large physical activity; hence, this method is advisable for T2DM patients who are unable to do exercises. A study done by Bathaie et al showed that diabetic rats treated with HTT experience HSP70 increase, significant improvement in lipid profile, antioxidant capacity, and insulin secretion, as well as a significant decrease in AGE formation when compared with untreated diabetic rats. However, HTT has a significant borderline effect on body weight and fasting blood glucose levels. ${ }^{63}$ Besides that, there is lipid profile improvement with a significantly increased level of TG, TC, and LDL-c in diabetic rats without any treatment when compared with the control group. However, the rats group with HTT showed a decreased level of all three lipid profiles. On the other hand, lowering HDL-c in diabetic rats experienced a significant increase when the diabetic rats were treated with HTT. $^{63}$

\section{HSP70 Modulation as a Therapeutic Target in T2DM by aHSP70 Internasal Administration}

Direct administration of HSP70 can increase the HSP70 level in the body. Administrated HSP70 is a derivate from alfalfa plant or Medicago sativa; hence, it is named alfalfa- derived HSP70 (aHSP70). ${ }^{64}$ The structure of aHSP70 resembles the natural HSP70 produced by the body. Therefore, there is no difference in its function. ${ }^{15}$

A study done by Tytell et al examined aHSP70 in DM rats and the result shows a decreased level of HbA1C by $0.1 \%$. The outcome itself was not significant statistically due to the lack of sample size used and the short duration for the study which was only for 32 days. ${ }^{15}$

Administration of aHSP70 also affects in increasing insulin sensitivity. Insulin injection was done intraperitoneally in diabetic rats to test the hypothesis before administering the aHSP70. Insulin sensitivity showed improvement by $14 \%$ and $40 \%$ after being administered with $10 \mu \mathrm{g}$ and $40 \mu \mathrm{g}$ aHSP70, respectively. ${ }^{15}$

It also indicates decreased blood glucose levels after aHSP70 administration and decreased insulin after aHSP70 treatment. A decrease in insulin concentration marks insulin sensitivity. Increased use of insulin by the body is supported by reduced blood glucose levels. The reduction in insulin level is significant in rats with the highest aHSP70 administration $(40 \mu \mathrm{g}){ }^{15}$

\section{Conclusion}

Through many of its roles in the inflammation process, mitochondrial function, and ER stress in insulin resistance pathogenesis, HSP70 has promising potency as a therapeutic target in managing T2DM. Several studies regarding HSP70modulating intervention have been proven able to decrease blood glucose, restore lipid profile, and improve insulin sensitivity. 


\section{Suggestion}

Due to limited studies regarding HSP70 and interventions to modulate it, subjected to lack in samples and short duration, further related studies, both preclinical and clinical trial, must be sustained.

\section{Author Contributions}

All authors contributed to data analysis, drafting or revising the article, gave final approval of the version to be published, and agree to be accountable for all aspects of the work.

\section{Disclosure}

There is no competing interest regarding the paper.

\section{References}

1. WHO. Global Report on Diabetes. Geneva: World Health Organization; 2016.

2. Mihardja L, Soetrisno U, Soegondo S. Prevalence and clinical profile of diabetes mellitus in productive aged urban Indonesians. $J$ Diabetes Investig. 2014;5(5):507-512. doi:10.1111/jdi.12177

3. Qaseem A, Barry MJ, Humphrey LL, Forciea MA. Oral pharmacologic treatment of type 2 diabetes mellitus: a clinical practice guideline update from the american college of physicians. Ann Intern Med. 2017;166(4):279-290. doi:10.7326/M16-1860

4. Lalau JD, Arnouts P, Sharif A, De Broe ME. Metformin and other antidiabetic agents in renal failure patients. Kidney Int. 2015;87 (2):308-322. doi:10.1038/ki.2014.19

5. Bennett WL, Maruthur NM, Singh S. Comparative effectiveness and safety of medications for type 2 diabetes: an update including new drugs and 2-drug combinations. Ann Intern Med. 2011;154:602-613. doi:10.7326/0003-4819-154-9-201105030-00336

6. Confederat L, Constantin S, Lupaşcu F, Pânzariu A, Hăncianu M, Profire L. Hypoglycemia induced by antidiabetic sulfonylureas. Rev Med Chir Soc Med Nat Iasi. 2015;119(2):579-584.

7. Fadini GP, Albiero M, de Kreutzenberg SV, Avogaro A. Hypoglycemia affects the changes in endothelial progenitor cell levels during insulin therapy in type 2 diabetic patients. $J$ Endocrinol Invest. 2015;38 (7):733-738. doi:10.1007/s40618-015-0247-1

8. Nanjan MJ, Mohammed M, Prashantha Kumar BR, Chandrasekar MJN. Thiazolidinediones as antidiabetic agents: A critical review. Bioorg Chem. 2018;77:548-567. doi:10.1016/j.bioorg.2018.02.009

9. Krause M, Heck TG, Bittencourt A, Scomazzon SP, Newsholme P, Curi R, Homem de Bittencourt PI. The chaperone balance hypothesis: the importance of the extracellular to intracellular HSP70 ratio to inflammation-driven type 2 diabetes, the effect of exercise, and the implications for clinical management. Mediators Inflamm. 2015;2015:249205. doi:10.1155/2015/249205

10. Krause M, Bock PM, Takahashi HK, Homem De Bittencourt PI, Newshole P. The regulatory roles of NADPH oxidase, intra- and extra-cellular HSP70 in pancreatic islet function, dysfunction and diabetes. Clin Sci. 2015;128(11):789-803. doi:10.1042/CS20140695

11. Kavanagh K, Flynn DM, Jenkins KA, Zhang L, Wagner JD. Restoring HSP70 deficiencies improves glucose tolerance in diabetic monkeys. Am J Physiol Endocrinol Metab. 2011;300(5):894-901. doi:10.1152/ajpendo.00699.2010

12. Esser N, Legrand-Poels S, Piette J, Scheen AJ, Paquot N. Inflammation as a link between obesity, metabolic syndrome and type 2 diabetes. Diabetes Res Clin Pract. 2014;105(2):141-150. doi:10.1016/j.diabres.2014.04.006
13. Archer AE, Von Schulze AT, Geiger PC. Exercise, heat shock proteins and insulin resistance. Philos Trans $R$ Soc Lond B Biol Sci. 2018;373(1738):20160529. doi:10.1098/rstb.2016.0529

14. Krause M, Ludwig MS, Heck TG, Takahashi HK. Heat shock proteins and heat therapy for type 2 diabetes: pros and cons. Curr Opin Clin Nutr Metab Care. 2015;18(4):374-380. doi:10.1097/MCO. 0000000000000183

15. Tytell M, Davis AT, Giles J, et al. Alfalfa-derived HSP70 administered intranasally improves insulin sensitivity in mice. Cell Stress Chaperones. 2018;23(2):189-194. doi:10.1007/s12192-017-0835-4

16. Zwirowski S, Klosowska A, Obuchowski I, et al. Hsp70 displaces small heat shock proteins from aggregates to initiate protein refolding. EMBO J. 2017;36(6):783-796. doi:10.15252/embj.2015 93378

17. Young JC. Mechanisms of the Hsp70 chaperone system. Biochem Cell Biol. 2010;88(2):291-300. doi:10.1139/O09-175

18. Brüning A, Jückstock J. Misfolded proteins: from little villains to little helpers in the fight against cancer. Front Oncol. 2015;5:47.

19. Malyshev I. HSP70 in Damaged Cells. In: Immunity, Tumors and Aging: The Role of HSP70. Springer Briefs in Biochemistry and Molecular Biology. 2013. doi:10.1007/978-94-007-5943-5_3

20. Kim JY, Han Y, Lee JE, Yenari MA. The 70-kDa heat shock protein (Hsp70) as a therapeutic target for stroke. Expert Opin Ther Targets. 2018;22(3):191-199. doi:10.1080/14728222.2018.1439477

21. Shrestha L, Young JC. Function and chemotypes of human Hsp70 chaperones. Curr Top Med Chem. 2016;16(25):2812-2828. doi:10.2174/1568026616666160413142028

22. Vega VL, Rodríguez-Silva M, Frey T, et al. Hsp70 translocates into the plasma membrane after stress and is released into the extracellular environment in a membrane-associated form that activates macrophages. J Immunol. 2008;180(6):4299-4307. doi:10.4049/ jimmunol.180.6.4299

23. Rodrigues-Krause J, Krause M, O'Hagan C, et al. Divergence of intracellular and extracellular HSP72 in type 2 diabetes: does fat matter? Cell Stress Chaperones. 2012;17(3):293-302. doi:10.1007/ s12192-011-0319-x

24. Kurucz I, Morva A, Vaag A, et al. Decreased expression of heat shock protein 72 in skeletal muscle of patients with type 2 diabetes correlates with insulin resistance. Diabetes. 2002;51(4):1102-1109. doi:10.2337/diabetes.51.4.1102

25. Bruce CR, Carey AL, Hawley JA, Febbraio MA. Intramuscular heat shock protein 72 and heme oxygenase-1 mRNA are reduced in patients with type 2 diabetes: evidence that insulin resistance is associated with a disturbed antioxidant defense mechanism. Diabetes. 2003;52(9):2338-2345. doi:10.2337/diabetes.52.9.2338

26. Molanouri SM, Mahdavi M, Quinn LS, Gharakhanlou S, Isanegad A. Effect of resistance exercise training on expression of Hsp70 and inflammatory cytokines in skeletal muscle and adipose tissue of STZ-induced diabetic rats. Cell Stress Chaperones. 2016;21 (5):783-791. doi:10.1007/s12192-016-0703-7

27. Krause M, Rodrigues-Krause Jda C. Extracellular heat shock proteins (eHSP70) in exercise: possible targets outside the immune system and their role for neurodegenerative disorders treatment. Med Hypotheses. 2011;76(2):286-290. doi:10.1016/j.mehy.2010.10.025

28. Jane JK, Dorothy DS. TLR4 and insulin resistance. Gastroenterol Res Pract. 2010;212563:1-11. doi:10.1155/2010/212563

29. Di Naso FC, Porto RR, Fillmann HS, et al. Obesity depresses the anti-inflammatory HSP70 pathway, contributing to NAFLD progression. Obesity (Silver Spring). 2015;23(1):120-129. doi:10.10 02/oby.20919

30. Solinas G, Becattini B. JNK at the crossroad of obesity, insulin resistance, and cell stress response. Mol Metab. 2017;6(2):174-184. doi:10.1016/j.molmet.2016.12.001

31. Pal M, Febbraio MA, Lancaster GI. The roles of c-Jun NH2-terminal kinases (JNKs) in obesity and insulin resistance. $J$ Physiol. 2016;594 (2):267-279. doi:10.1113/JP271457 
32. Madamanchi NR, Li S, Patterson C, Runge MS. Reactive oxygen species regulate heat-shock protein 70 via the JAK/STAT pathway. Arterioscler Thromb Vasc Biol. 2001;21(3):321-326. doi:10.1161/01. ATV.21.3.321

33. Molina MN, Feder L, Manucha W. Emerging role of nitric oxide and heat shock proteins in insulin resistance. Curr Hypertens Rep. 2016;18(1):1. doi:10.1007/s11906-015-0615-4

34. Radons J. The human HSP70 family of chaperones: where do we stand? Cell Stress Chaperones. 2016;21(3):379-404.

35. Morino K, Petersen KF, Shulman GI. Molecular mechanisms of insulin resistance in humans and their potential links with mitochondrial dysfunction. Diabetes. 2006;55(Suppl. 2):S9-S15. doi:10.2337/ db06-S002

36. Patti ME, Butte AJ, Crunkhorn $\mathrm{S}$, et al. Coordinated reduction of genes of oxidative metabolism in humans with insulin resistance and diabetes: potential role of PGC1 and NRF1. Proc Natl Acad Sci. 2003;100(4):8466-8471. doi:10.1073/pnas.1032913100

37. Petersen KF, Dufour S, Befroy D, Garcia R, Shulman GI. Impaired mitochondrial activity in the insulin-resistant offspring of patients with type 2 diabetes. $N$ Engl J Med. 2004;350(7):664-671. doi:10.1056/NEJMoa031314

38. Gupte AA, Bomhoff GL, Swerdlow RH, Geiger PC. Heat treatment improves glucose tolerance and prevents skeletal muscle insulin resistance in rats fed a high-fat diet. Diabetes. 2009;58(3):567-578. doi: $10.2337 / \mathrm{db} 08-1070$

39. Chen HW, Chen SC, Tsai JL, Yang RC. Previous hyperthermic treatment increases mitochondria oxidative enzyme activity and exercise capacity in rats. Kaohsiung J Med Sci. 1999;15(10):572-580.

40. Tamura Y, Kitaoka Y, Matsunaga Y, Hoshino D, Hatta H. Daily heat stress treatment rescues denervation-activated mitochondrial clearance and atrophy in skeletal muscle. $J$ Physiol. 2015;593 (12):2707-2720. doi:10.1113/JP270093

41. Liu C-T, Brooks GA. Mild heat stress induces mitochondrial biogenesis in C2C12 myotubes. J Appl Physiol. 2012;112(3):354-361. doi:10.1152/japplphysiol.00989.2011

42. Chung J, Nguyen AK, Henstridge DC, et al. HSP72 protects against obesity-induced insulin resistance. Proc Natl Acad Sci USA. 2008;105(5):1739-1744. doi:10.1073/pnas.0705799105

43. Henstridge DC, Bruce CR, Drew BG, et al. Activating HSP72 in rodent skeletal muscle increases mitochondrial number and oxidative capacity and decreases insulin resistance. Diabetes. 2014;63 (6):1881-1894. doi:10.2337/db13-0967

44. Boutant M, Canto C. SIRT1 metabolic actions: integrating recent advances from mouse models. Mol Metab. 2014;3(1):5-18 doi:10.1016/j.molmet.2013.10.006

45. Baar K, Wende AR, Jones TE, et al. Adaptations of skeletal muscle to exercise: rapid increase in the transcriptional coactivator PGC-1. FASEB J. 2002;16(14):1879-1886. doi:10.1096/fj.02-0367com

46. Goto M, Terada S, Kato M, et al. cDNA cloning and mRNA analysis of PGC-1 in epitrochlearis muscle in swimming-exercised rats Biochem Biophys Res Commun. 2000;274(2):350-354. doi:10.1006/ bbrc. 2000.3134

47. Norrbom J, Sundberg CJ, Ameln H, Kraus WE, Jansson E, Gustafsson T. PGC-1alpha mRNA expression is influenced by metabolic perturbation in exercising human skeletal muscle. J Appl Physiol. 2004;96(1):189-194. doi:10.1152/japplphysiol.00765.2003

48. Drew BG, Ribas V, Le JA, et al. HSP72 is a mitochondrial stress sensor critical for Parkin action, oxidative metabolism, and insulin sensitivity in skeletal muscle. Diabetes. 2014;63(5):1488-1505. doi: $10.2337 / \mathrm{db} 13-0665$

49. Ron D, Walter P. Signal integration in the endoplasmic reticulum unfolded protein response. Nat Rev Mol Cell Biol. 2007;8 (7):519-529. doi:10.1038/nrm2199
50. Schroder M, Kaufman RJ. The mammalian unfolded protein response. Annu Rev Biochem. 2005;74:739-789. doi:10.1146/ annurev.biochem.73.011303.074134

51. Fu S, Yang L, Li P, et al. Aberrant lipid metabolism disrupts calcium homeostasis causing liver endoplasmic reticulum stress in obesity. Nature. 2011;473(7348):528-531. doi:10.1038/nature09968

52. Kammoun HL, Chabanon H, Hainault I, et al. GRP78 expression inhibits insulin and ER stress-induced SREBP-1c activation and reduces hepatic steatosis in mice. J Clin Invest. 2009;119 (5):1201-1215. doi:10.1172/JCI37007

53. Lee JN, Ye J. Proteolytic activation of sterol regulatory element-binding protein induced by cellular stress through depletion of Insig-1. J Biol Chem. 2004;279(43):45257-45265. doi:10.1074/ jbc.M408235200

54. Ozcan U, Yilmaz E, Ozcan L, et al. Chemical chaperones reduce ER stress and restore glucose homeostasis in a mouse model of type 2 diabetes. Science. 2006;313(5790):1137-1140. doi:10.1126/science. 1128294

55. Falcone JA, Salameh TS, Yi X, et al. Intranasal administration as a route for drug delivery to the brain: evidence for a unique pathway for albumin. J Pharmacol Exp Ther. 2014;351(1):54-60. doi:10.1124/ jpet.114.216705

56. Dash S, Xiao C, Morgantini C, Koulajian K, Lewis GF. Intranasal insulin suppresses endogenous glucose production in humans compared with placebo in the presence of similar venous insulin concentrations. Diabetes. 2015;64(3):766-774. doi:10.2337/db140685

57. Kimura K, Tanida M, Nagata N, et al. Central insulin action activates Kupffer cells by suppressing hepatic vagal activation via the nicotinic alpha 7 acetylcholine receptor. Cell Rep. 2016;14(10):2362-2374. doi:10.1016/j.celrep.2016.02.032

58. Yamada P, Amorim F, Moseley P, Schneider S. Heat shock protein 72 response to exercise in humans. Sports Med. 2008;38(9):715-733. doi:10.2165/00007256-200838090-00002

59. Liu Y, Steinacker JM. Changes in skeletal muscle heat shock proteins: pathological significance. Front Biosci. 2001;6:D12-D25. doi:10.2741/liu

60. Febbraio MA, Koukoulas I. HSP72 gene expression progressively increases in human skeletal muscle during prolonged, exhaustive exercise. J Appl Physiol. 2000;89(3):1055-1060. doi:10.1152/jappl. 2000.89.3.1055

61. Noble EG, Ho R, Dzialoszynski T. Exercise is the primary factor associated with Hsp70 induction in muscle of treadmill running rats. Acta Physiol. 2006;187(4):495-501. doi:10.1111/aps.2006.187.issue4

62. Tsuzuki T, Kobayashi H, Yoshihara T, Kakigi R, Ichinoseki-Sekine N, Naito H. Attenuation of exercise-induced heat shock protein 72 expression blunts improvements in whole-body insulin resistance in rats with type 2 diabetes. Cell Stress Chaperones. 2017;22 (2):263-269. doi:10.1007/s12192-017-0767-z

63. Bathaie SZ, Jafarnejad A, Hosseinkhani S, Nakhjavani M. The effect of hot-tub therapy on serum Hsp70 level and its benefit on diabetic rats: a preliminary report. Int $J$ Hyperthermia. 2010;26(6):577-585. doi:10.3109/02656736.2010.485594

64. Ferradini N, Iannacone R, Capomaccio S, et al. Assessment of heat shock protein 70 induction by heat in alfalfa varieties and constitutive overexpression in transgenic plants. PLoS One. 2015;10(5):0126051. doi:10.1371/journal.pone.0126051

65. Artha IMJR, Bhargah A, Dharmawan NK, et al. High level of individual lipid profile and lipid ratio as a predictive marker of poor glycemic control in type-2 diabetes mellitus. Vasc Health Risk Manag. 2019;15:149-157. doi:10.2147/VHRM.S209830 


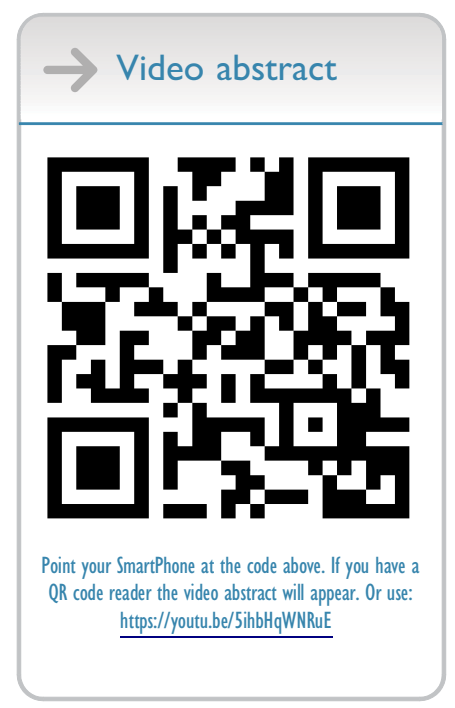

Diabetes, Metabolic Syndrome and Obesity: Targets and Therapy

\section{Publish your work in this journal}

Diabetes, Metabolic Syndrome and Obesity: Targets and Therapy is an international, peer-reviewed open-access journal committed to the rapid publication of the latest laboratory and clinical findings in the fields of diabetes, metabolic syndrome and obesity research. Original research, review, case reports, hypothesis formation, expert opinion and commentaries are all considered for publication. The manuscript management system is completely online and includes a very quick and fair peer-review system, which is all easy to use. Visit http://www.dovepress.com/testimonials.php to read real quotes from published authors. 